\title{
Long-term Outcome after Surgical Closure of Atrial Septal Defect in Childhood with Extensive Assessment Including MRI Measurement of the Ventricles
}

\author{
D. Bolz, ${ }^{1}$ T. Lacina, ${ }^{2}$ P. Buser, ${ }^{3}$ M. Buser, ${ }^{3}$ J. Guenthard ${ }^{1}$ \\ ${ }^{1}$ Division of Cardiology, University Children's Hospital, Roemergasse 8, 4005 Basel, Switzerland \\ ${ }^{2}$ Department of Radiology, University Hospital, Petersgraben 4, 4031, Basel, Switzerland \\ ${ }^{3}$ Division of Cardiology, University Hospital, Petersgraben 4, 4031, Basel, Switzerland
}

\begin{abstract}
Surgical closure of the secundum type of atrial septal defect (ASD) in childhood leads to excellent survival. However, relevant morbidity has been reported. Transcatheter closure of these defects has now become an alternative approach. To compare the results of the two different interventions, reliable data are needed on the long-term morbidity after defect closure with both methods. Patients were evaluated after a minimum of 10 years after surgical closure of an ASD in childhood. Assessment included analysis of perioperative data, interview, clinical examination, electrocardiogram, (ECG), 24-hour ECG, ergometry, chest radiograph, echocardiography, and MRI. A total of 66 patients underwent operation between 1971 and 1986 at our institution. Forty-eight of them $(73 \%)$ were interviewed and 38 $(58 \%)$ participated fully in the study program. Eighteen $(27 \%)$ either refused to participate or were lost to follow-up. There were no substantial residual disorders, such as arrhythmias, right-sided heart dilatation, pulmonary hypertension, or reduced work capacity. Surgical closure of an ASD in childhood has an excellent long-term outcome. Surgical closure is thus the standard against which transcatheter closure needs to be measured.
\end{abstract}

Key words: Atrial septal defect - Surgical closure Transcatheter closure - Long-term outcome

In children, surgical closure of an atrial sepal defect (ASD) results in long-term survival not significantly different from that of a matched control population. Moreover, studies of long-term morbidity have shown better results for surgical closure in childhood as compared with closure in adults [8, 13-17, 22]. Therefore, it is generally accepted that an ASD with a

Correspondence to: D. Bolz, email: dieter.bolz@unibas.ch hemodynamically relevant left-to-right shunt needs to be closed during childhood.

During the past 10 years, studies of surgical closure have centered on survival according to age at operation. Findings related to long-term morbidity were mainly based on questionnaires and interviews $[13,16,17]$. Only a few studies have evaluated consecutive patient series after operation in childhood and assessed the clinical sequelae during long-term follow-up, and only Meijboom et al. and RoosHesselink et al. included bicycle ergometry and 24-hour electrocardiograms (ECG) in their studies $[14,22]$. Transcatheter closure with an occluding device is an alternative method that nowadays is also used frequently in children. Considering the excellent results after surgical closures, the question arises of whether the advantages of transcatheter closure (no cardiopulmonary bypass, no thoracotomy or scar, shorter hospital stay, lower costs) justify its use in children with respect to the long-term outcome [5, 7, $10,27]$. Because information on long-term morbidity is sparse, the aim of this study was to provide additional data on the long-term outcome in patients with surgical closure of an ASD in childhood. Our investigation is based on an analysis of work capacity and the presence or absence of arrhythmias and is further extended by an assessment of the geometry and function of the ventricles by MRI.

\section{Methods}

\section{Inclusion Criteria}

All children $(<16$ years) who underwent surgical closure of the secundum or sinus venosus type of an ASD between 1971 and 1986 at the University Hospital in Basel, Switzerland, were included. Patients with associated cardiac lesions, except for partial anomalous pulmonary venous return or mild pulmonary stenosis, were 
excluded. The minimum follow-up time was 10 years. Written informed consent was obtained from all patients or from their parents.

\section{Patients}

A total of 66 children were included in this study. The operative techniques included right lateral thoracotomy or median sternotomy, complete cardiopulmonary bypass, and patch or direct suture of the defect. Fifty-five patients $(83 \%)$ had a defect of the secundum type, and eleven patients $(17 \%)$ had a defect of the sinus venosus type. Seven patients (11\%) had partial anomalous pulmonary venous return, and five patients (8\%) had a mild pulmonary stenosis. In one patient a patent ductus, due to prematurity, had been closed in the neonatal period. There were 42 female patients (64\%) and 24 males patients (36\%). Prior to the surgical intervention, heart catheterization had been performed in all 66 patients. Of the total of 66 patients, 48 (73\%) were interviewed and $38(58 \%)$ underwent full evaluation, whereas five $(8 \%)$ declined to participate and $13(20 \%)$ were lost to follow-up. Because we could not examine all of the patients, we compared the pre- and perioperative data of all 66 patients to exclude a possible selection bias.

\section{Interview}

Patients were questioned about their current health, cardiac and noncardiac problems or diseases, medications, professional status, and recreational physical activities.

\section{Clinical Evaluation}

We performed complete cardiologic assessment with a physical examination, standard 12-lead ECG, 24-hour ECG, bicycle ergometry, chest radiograph (frontal plane), transthoracic echocardiography (two dimensional, M-mode, pulsed- and continuous-wave, and color-flow Doppler), and MRI (measuring volumes and function of the right and left ventricle).

\section{Standard Electrocadiogram}

Standard 12-lead ECG was performed (Portrait model; Mortara Instrument Inc., Milwaukee, WI). To compare the results we selected the following criteria in accordance with Meijboom et al. [14]: (1) First-degree atrioventricular block was defined as an atrioventricular conduction time of $>0.2$ seconds, (2) right bundle branch block was defined as an RSR' pattern of the QRS complex with a duration of $>0.12$ seconds, (3) right ventricular hypertrophy as a heart axis between $90^{\circ}$ and $180^{\circ}$ and $\mathrm{R}$ or $\mathrm{R}^{\prime}>0.5 \mathrm{mV}$ in lead $\mathrm{V}_{1}$ or $\mathrm{R}>\mathrm{S}$ in lead $\mathrm{V}_{1}$ in the absence of a right bundle branch block.

\section{Ambulatory 24-hour Electrocardiogram}

Ambulatory 24-hour ECG was recorded and analyzed using the Portrait model and the Marquette Electronics series 8500 model (Milwaukee, WI). Abnormal ventricular ectopy was diagnosed by the occurrence of $>30$ monoform premature ventricular contrac- tions within any hour, or the presence of multiform premature ventricular contractions, or the presence of couplets, or the occurrence of tachycardia. Abnormal supraventricular ectopy was defined as $>30$ premature supraventricular beats in any hour and/ or tachycardia. Sinus node dysfunction was defined as described by Kugler [12].

\section{Bicycle Ergometry}

We performed bicycle ergometry with the Ergometer 900 model (Ergoline Cardiosystems, Bitz, Germany). We assessed exercise capacity with stepwise increments of workload as described earlier by James et al. and compared our results with the reported normal values, corrected for age, sex, and height, of the same study [11].

\section{Echocardiography}

We performed complete two-dimensional and color-flow Doppler imaging as well as M-mode, pulsed-wave, and continuous-wave Doppler with the Sonos 1000 model, $5.0-\mathrm{MHz}$ and $2.5-\mathrm{MHz}$ probes (Hewlett Packard, Palo Alto, CA). The results were compared with normal values corrected for body surface area (BSA) [25].

\section{Magnetic Resonance Imaging}

MRI was done with a 1.5-T whole-body scanner (Siemens Vision Unit model; Siemens AG, Erlangen, Germany) using ECG gated sequences. We assessed volumes and function of the right and left ventricle and compared the results with reported normal values [21].

\section{Data Analysis}

Data are presented as median and mean values with SD and ranges. Statistical analysis was performed with Fisher's exact test, the Kruskal-Wallis test, and the Wilcoxon-Mann-Whitney test; $p$ value $<0.05$ was considered to be significant.

\section{Ethics}

The study was approved by the local ethics committee, and the procedures were performed in accordance with institutional guidelines.

\section{Results}

\section{Pre- and Perioperative Data}

Baseline characteristics of the 66 patients operated on within the period we analyzed are summarized in Table 1. There were no perioperative deaths. Two patients required an early postoperative intervention. One was reoperated on on the second day because of a hematoma that caused occlusion of the drainage of 
Table 1. Baseline characteristics of patients with both interview and follow-up examination $(n=38)$, patient with interview only $(n=10)$, and patients refusing to participate or not found $(n=18)$

\begin{tabular}{lccc}
\hline & $\begin{array}{c}\text { Interview and examination } \\
\text { mean } \pm \mathrm{SD} \text { (median/range) }\end{array}$ & $\begin{array}{c}\text { Interview only } \\
\text { mean } \pm \mathrm{SD} \text { (median/range) }\end{array}$ & $\begin{array}{c}\text { Without follow-up } \\
\text { mean } \pm \text { SD (median/range) }\end{array}$ \\
\hline Age at operation (yr) & $6.5 \pm 3.3(5.1 / 3.5-15.6)$ & $7.1 \pm 2.3(6.9 / 4.1-11.0)$ & $7.4 \pm 3.6(5.7 / 3.5-13.4)$ \\
Follow-up time (yr) & $20.3 \pm 5.0(21.8(11.0-26.3)$ & $19.9 \pm 5.0(21.6 / 12.2-27.2)$ & $20.5 \pm 3.8(20.8 / 13.7-26.5)$ \\
Qp:Qs & $2.4 \pm 0.6(2.3 / 1.6-4.2)$ & $2.0 \pm 0.4(2.0 / 1.3-2.5)$ & $2.5 \pm 0.6(2.5 / 1.6-3.5)$ \\
Pulmonary artery peak & $23 \pm 5(22 / 15-35)$ & $25 \pm 5.5(24 / 17-35)$ & $22 \pm 3.7(22 / 17-30)$ \\
systolic pressure (mmHg) & & & 28 \\
Cardioplegia (\%) & 32 & 40 & 0 \\
Patch closure (\%) & 7.9 & $1: 1$ & $1.8: 1$ \\
Sex ratio (F:M) & $1.6: 1$ & & \\
\hline
\end{tabular}

There were no statistically significant differences among the three groups.

${ }^{a}$ Ratio of pulmonary (Qp) to systemic (Qs) blood flow.

the pleural space; the other had a pleural effusion that was drained via a single puncture on the sixth postoperative day. There were no perioperative arrhythmias and no reoperations due to a residual shunt. There were no significant differences among the patients who participated fully in the overall follow-up program, the patients who were interviewed by telephone, and the nonparticipating patients in terms of sex, age at operation, operative technique, associated lesions, shunt volume, pulmonary artery pressure, perioperative complications, or follow-up time.

\section{Structured Interview}

Forty-four of the 48 interviewed patients (92\%) considered themselves to be healthy. Four patients reported an impaired exercise capacity, and one of them suffered from narcolepsy. One patient, who was suffering from a depressive mental disorder, was taking antipsychotic drugs. Except for the latter patient, all of the others had completed secondary school and entered a profession that required further training. Four patients had completed a tertiary academic education.

None of the patients had any documented arrhythmia, but three patients reported episodes of rapid or irregular heart beat and nine patients reported short episodes of chest pain, primarily in situations of mental stress. Two patients reported both of these symptoms. None of them took antiarrhythmic or other cardiac medication. None of them required a pacemaker. Seven patients (six female and one male) complained about the negative cosmetic impact of their scars (two with a right anterior thoracotomy, five with a sternotomy).

The 10 patients who had been interviewed but did not undergo the full evaluation and reported themeselves as well were reported by their family doctors to have no abnormal cardiovascular findings.

\section{Physical Examination}

All of the 38 patients who participated fully in the overall study were in good health. Nine were overweight, with a body mass index between 25.5 and 29.8. One patient had a systolic and diastolic heart murmur due to mild stenosis and incompetence of the pulmonary valve. In 16 patients, auscultation revealed innocent heart murmurs. Six female patients, all with a sternotomy, showed mild to moderate thickening of their scars. Three of them had complained about the unsightliness of their scars.

\section{Standard 12-lead Surface Electrocardiogram}

The ECG revealed that all 38 patients were in sinus rhythm. Two patients had a complete right bundle branch block. No atrio-ventricular block or right ventricular hypertrophy was observed.

\section{Ambulatory 24-hour Electrocardiogram}

Thirty-six of the 38 patients were examined. None of them reported any symptoms during the recording. Two patients had a short episode of supraventricular tachycardia, with six and eight beats, respectively. Two showed ventricular ectopic activity. One of them had 17 single multiform premature ventricular beats in 24 hours; the other one had 378 single premature ventricular beats in 24 hours, but they were of the monoform type and the maximum number of premature beats per hour (35/hour) was only slightly above the defined limit. None of these patients had a 
history of rapid or irregular heart beat or episodes of chest pain.

\section{Bicycle Ergometry}

Workload capacity was tested in all 38 patients. No arrhythmias were observed in any patient either during or shortly after exercise. The study group had a slightly lower mean work capacity as compared with normal values; however, the difference did not reach statistical significance (i.e., the percentage of subjects with a work capacity below the population mean was not significantly different from 50\%). Maximal and mean work capacity according to gender and height compared with normal values is shown in Figs. 1 and 2. In two patients, the values of the maximal and mean work capacity were more than two SD below the mean value of normal subjects. In two other patients, the values of the mean work capacity were more than two SD below the mean value of normal subjects [11]. The group of patients with diminished work capacity did not differ from those with normal work capacity in any of the perioperative parameters and the findings on follow-up examinations, e.g., shunt size, age at operation, time of follow-up, size and function of the ventricles by echocardiography, and MRI.

\section{Chest Radiograph}

Four of the 38 patients showed borderline cardiomegaly, with a cardiothoracic index of 0.50 in three patients and 0.52 in the fourth one. The mean value of the index in the whole study group was $0.46 \pm 0.03$ (range, 0.40-0.52), which is within the normal range of healthy subjects $[6,26]$. In 10 patients, the pulmonary arteries - in particular, the large central vessels - were slightly prominent. The two patients with a residual ASD were among these 10 patients.

\section{Transthoracic Echocardiography}

Two of the 38 patients had a small residual ASD (4 and $5 \mathrm{~mm}$, respectively). The dimensions of the right and left ventricles are shown in Table 2. The dimensions of both ventricles in all 38 patients were within normal limits [25]. The ejection fraction (normal values, $>55 \%$ ) of the left ventricle had a mean value of $63 \pm 6 \%$ (median, $62 \%$; range, 53\%-80\%). The patient with the slightly impaired ejection fraction of $53 \%$ had a normal fractional shortening of $37 \%$ (normal values, $>28 \%$ ). The fractional short-
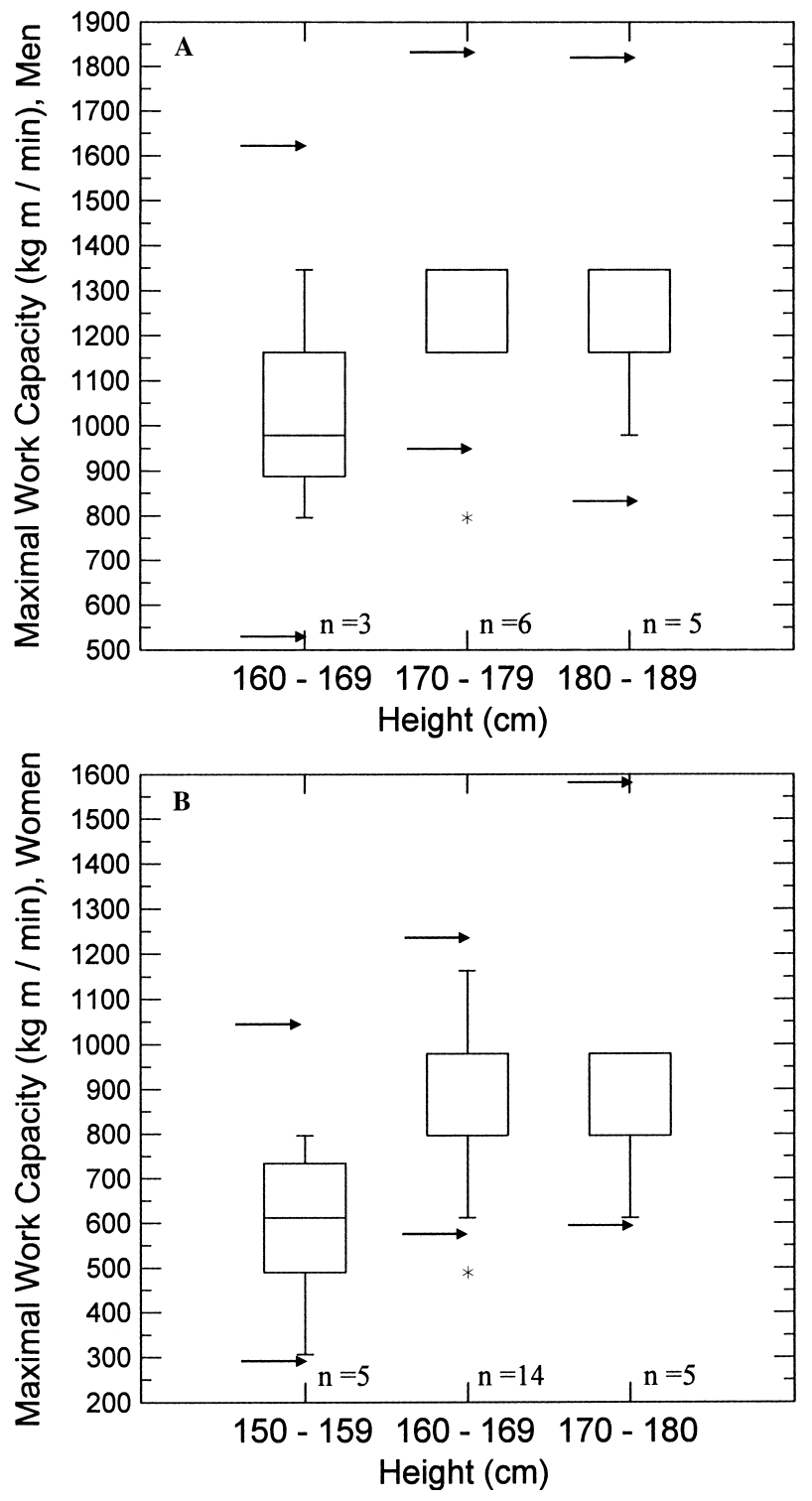

Fig. 1. Maximal work capacity of the three height groups of the male (a) and female (b) patients. The arrows indicate the range of normal subjects [11]. The differences were not statistically significant.

ening of the left ventricle had a mean value of $39 \pm 5 \%$ (median, 40\%; range, 28-47\%). No hemodynamically significant abnormalities were identified. Mild tricuspid regurgitation was observed in 12 of the 38 patients. The peak pressure gradient between the right ventricle and the right atrium was $17 \pm 3$ $\mathrm{mmHg}$ (median, 17; range, 12-23) in these 12 patients. Twenty four patients had minimal pulmonary regurgitation, with an end diastolic pressure gradient of $1.6 \pm 0.7 \mathrm{mmHg}$. In seven patients, there was an abnormal ventricular septal motion; however, only one patient had a paradoxical pattern. Mild mitral regurgitation was observed in one patient. 

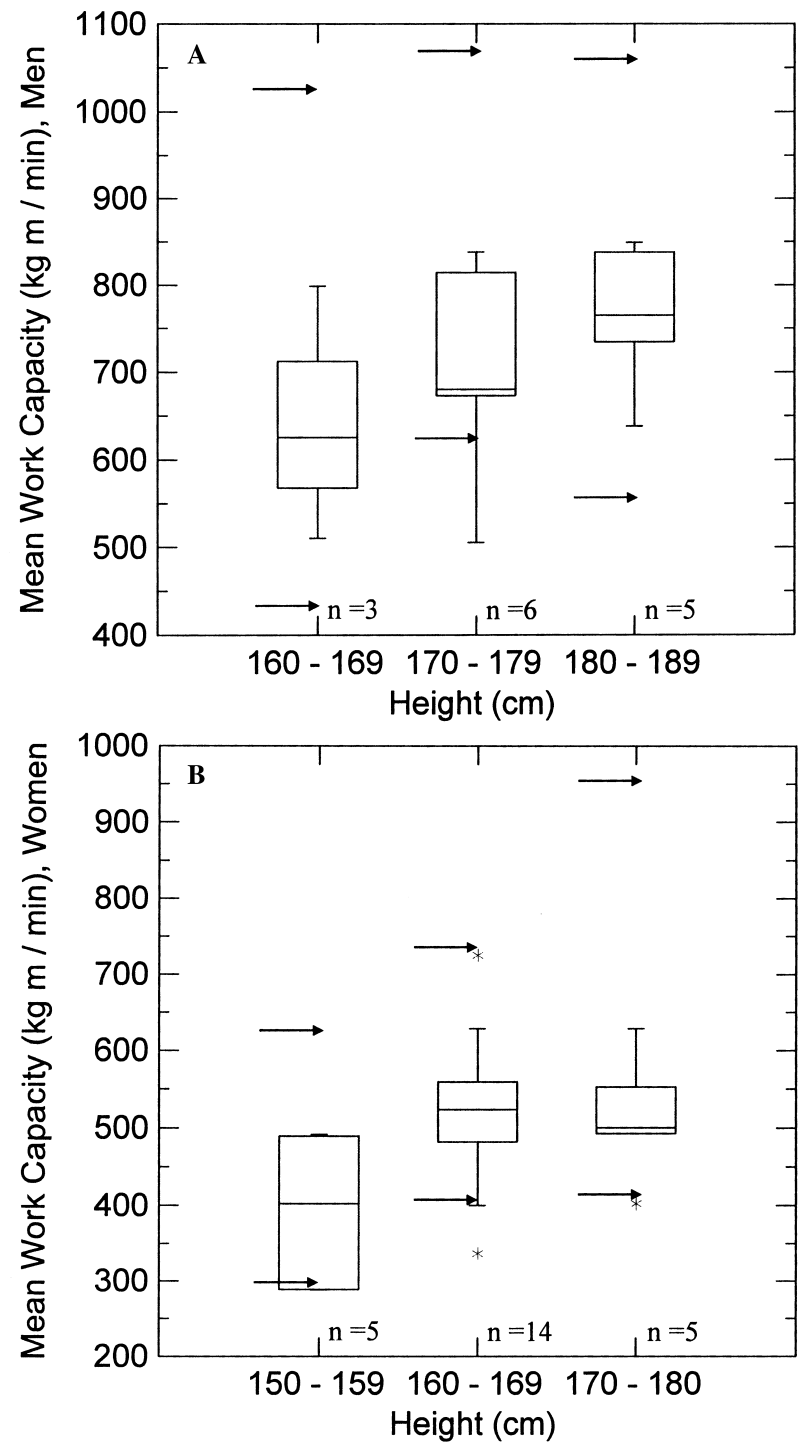

Fig. 2. Mean work capacity of the three height groups of the male (a) and female (b) patients. The arrows indicate the range of normal subjects [11]. The differences were not statistically significant.

\section{Magnetic Resonance Imaging}

MRI was performed in 32 of the 38 patients. Six patients did not undergo MRI because there was an accidental death; five other patients refused to undergo this examination. All subjects had normal right and left ventricular end diastolic volumes, with indexes of $58 \pm 15$ and $62 \pm 15 \mathrm{ml}$ per $\mathrm{m}^{2}$ BSA, respectively [21]. The ejection fraction of the right ventricle was $58 \pm 6 \%$. In three patients, the ejection fraction was slightly below the normal limit of $49 \%$, with values of $45 \%, 46 \%$, and $48 \%$, respectively [21]. The ejection fraction of the left ventricle was $63 \pm 6 \%$. Only one patient had a value of $51 \%$, which was slightly below the normal limit of $54 \%$. The volumes and ejection fractions of both ventricles are shown in Figs. 3-5.

\section{Discussion}

In our follow-up study of patients at 11-26 years (median, 22) after the surgical closure of an ASD in childhood, we performed a comprehensive examination of long-term cardiac morbidity in these cases. Such an extended study of a consecutive patient cohort, including ventricular assessment by MRI, has not been previously reported. This complete assessment of cardiac sequelae provides additional data for comparative studies with individuals who undergo transcatheter closure of an ASD in childhood.

Most of the patients (92\%) felt well and healthy. None of them required surgical reintervention or medical treatment, and none of them had a substantial residual disorder.

Arrhythmias, a major concern in late follow-up, did not occur in our patients. This finding contradicts the results of a number of earlier studies in which arrhythmias were reported in $\leq 71 \%$ of subjects $[2,3,14,16,20,23,24]$. Many of these studies were conducted in the early days of open heart surgery with cardiopulmonary bypass. Since that time, experience has grown and surgical techniques have improved, no doubt contributing to the better results seen with our patients. This hypothesis is supported by the report of Bink-Boelkens et al., which documents the vast strides that have been made in surgical technique [2]. Moreover, the recent study by Ross-Hesselink et al., which has a very a long followup time (mean, 26 years), also reported a low incidence of arrhythmias (8\%) [22].

In our study population, we did not observe pulmonary hypertension either in the preoperative examinations or on follow-up. This is consistent with the findings of Roos-Hesselink et al. [22]. However, earlier studies described cohorts with severe preoperative pulmonary hypertension, even in children $[1,4,9,17,19]$. For instance, in Cherian et al.'s. study of 709 young patients, the incidence of pulmonary hypertension (systolic pulmonary artery pressure $>50 \mathrm{mmHg}$ ) was $13 \%$ in children under 10 years of age [4]. In a study conducted by Murphy et al., the incidence of pulmonary hypertension within the same age group was even higher at $28 \%$ (peak systolic pulmonary artery pressure $>40 \mathrm{mmHg}$ ) [17]. Because diagnosis by echocardiography was not possible at that time, there was probably a selection bias whereby the study populations included only severely symptomatic patients. 
Table 2. Two-dimensional and M-mode echocardiography of Ventricular dimensions of the left and right ventricles of patients and normal subjects [25]

\begin{tabular}{|c|c|c|c|c|}
\hline & $\begin{array}{l}\text { Patients }(n=38) \\
\text { mean } \pm 2 \mathrm{SD} \\
(\text { median/range })(\mathrm{mm})\end{array}$ & $\begin{array}{l}\text { Normal subjects } \\
\text { mean } \pm 2 \mathrm{SD} \\
\text { (range) }(\mathrm{mm})\end{array}$ & $\begin{array}{l}\text { Patients }(n=38) \\
\text { mean } \pm 2 \mathrm{SD}(\text { median/range }) \\
\left(\mathrm{mm} / \mathrm{m}^{2} \text { BSA }\right)\end{array}$ & $\begin{array}{l}\text { Normal subjects } \\
\text { (range) }\left(\mathrm{mm} / \mathrm{m}^{2} \text { BSA) }\right.\end{array}$ \\
\hline \multicolumn{5}{|c|}{ 4-Chamber view } \\
\hline RVEDD & $\begin{array}{l}33 \pm 10 \\
(34 / 20-42)\end{array}$ & $\begin{array}{l}33 \pm 11 \\
(22-45)\end{array}$ & $\begin{array}{l}19 \pm 4 \\
(19 / 14-22)\end{array}$ & $\overline{(10-28)}$ \\
\hline LVEDD & $\begin{array}{l}45 \pm 10 \\
(44 / 36-55)\end{array}$ & $\begin{array}{l}47 \pm 14 \\
(38-62)\end{array}$ & $\begin{array}{l}26 \pm 6 \\
(26 / 21-33)\end{array}$ & $\overline{(22-31)}$ \\
\hline \multicolumn{5}{|l|}{ M-mode } \\
\hline LVEDD & $\begin{array}{l}48 \pm 8 \\
(48 / 40-62)\end{array}$ & $\begin{array}{l}48 \pm 13 \\
(38-61)\end{array}$ & $\begin{array}{l}27 \pm 6 \\
(27 / 22-33)\end{array}$ & $\overline{(23-32)}$ \\
\hline
\end{tabular}

BSA, body surface area; LVEDD, left ventricular end diastolic diameter; RVEDD, right ventricular end diastolic diameter.

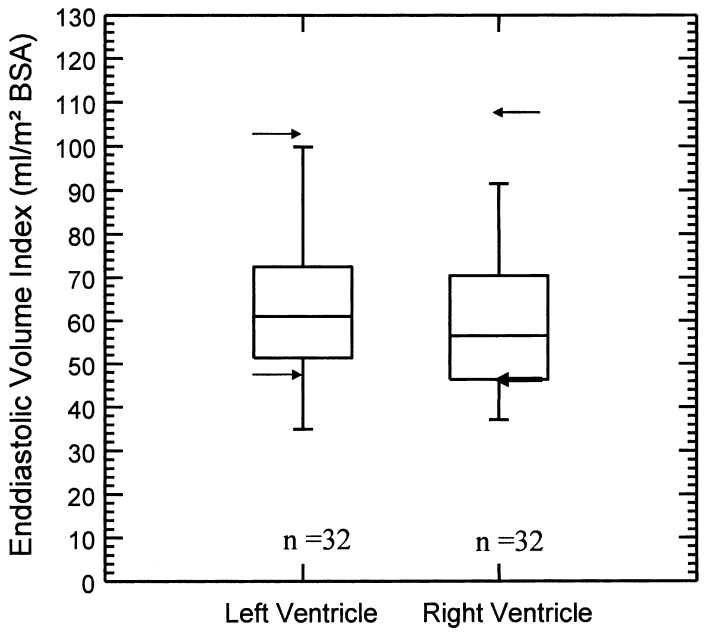

Fig. 3. Left and right ventricular end diastolic volume index by MRI. The arrows indicate the range of normal subjects [21]. BSA, body surface area.

In contrast to other studies showing a high incidence of persistent dilatation of the right ventricle in $20 \%$ to $80 \%$ of subjects, all of our patients had right and left ventricles with normal diameters $[14,15,22$, 29]. It is important to note that these echocardiographic findings were confirmed by measurement of ventricular volumes using MRI, which is recognized as the gold standard for the assessment of cardiac ventricular volumes.

The work capacity of our patients was slightly diminished compared with that of normal subjects, but the difference was not statistically significant [11]. The probable explanation is that 26 of the 38 patients did not engage in any sports or recreational physical activities. The reduced exercise capacity we found in five patients was not due to cardiac problems. Our results are comparable with those re-

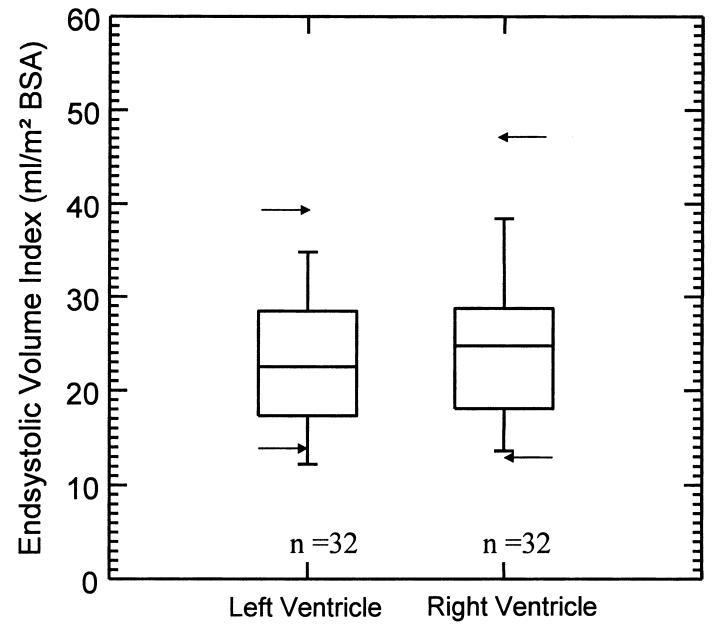

Fig. 4. Left and right ventricular end systolic volume index by MRI. The arrows indicate the range of normal subjects [21]. BSA, body surface area.

ported by Meijboom et al. and Roos-Hesselink et al $[14,22]$.

We found a small, hemodynamically irrelevant residual ASD in two patients (5\%). This figure is comparable with the incidence of $7.5 \%$ reported by Pastorek et al. in 1994 [18].

Our study focused on the cardiac outcome. We did not formally assess neurocognitive function. In our opinion, this type of study needs to be performed preoperatively and prospectively, which was not possible in this retrospective analysis. However, data on the neurocognitive function of our patients were obtained through the assessment of their later educational and professional achievements. In our opinion, these data indirectly reflect the absence of any major impairment. Developmental outcome after ASD closure using both methods was studied by Visconti et al. In that study, they found visual-spatial 


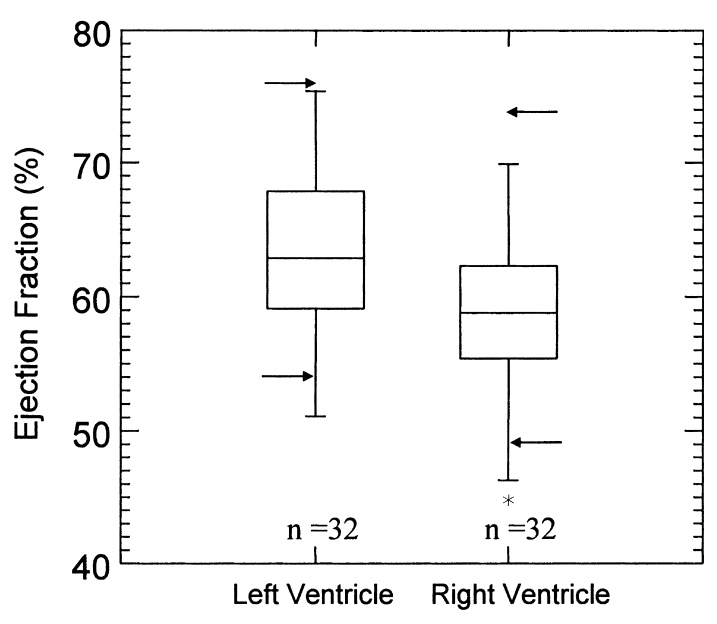

Fig. 5. Left and right ventricular ejection fraction (\%) by MRI. The arrows indicate the range of normal subjects [21].

and visual-motor skill deficits in the surgical group and a significantly reduced index of attentiveness in the transcatheter closure group [28]. However, there was no difference between these two groups in academic achievement, language skills, or memory. Because of the small number of study participants, possible selection bias, and lack of preoperative testing, these observations remain inconclusive and confirmation is necessary.

In our study, only seven patients (six females and one male) reported a negative impact from the surgical scars. One female patient is considering corrective cosmetic surgery. It should be noted that newer surgical techniques result in less visible and smaller scars, hence mitigating the disadvantages of the surgical approach to ASD closure.

Other recently published studies comparing surgical vs. transcatheter closure have reported good short-term outcomes [5, 10, 27]. A comparison of the two methods in terms of late cardiac morbidity is as yet unavailable.

\section{Conclusions}

Our study shows that the long-term results after surgical closure of an ASD in childhood are excellent. The good outcome documented in our study, in contrast to others, is further supported by our precise assessment of the volume and function of the ventricles. Our findings provide baseline data for the assessment of the efficacy of transcatheter closure of such defects. In addition, we did not detect any major neurocognitive dysfunction; however, it needs be said that the study was not designed primarily to assess this parameter.

Acknowledgment. We are indebted to Christian Schindler for the statistical analysis.

\section{References}

1. Besterman E (1961) Atrial septal defect with pulmonary hypertension. Br Heart $J$ 23:587-598

2. Bink-Boelkens MTE, Meuzelaar KJ, Eygelaar A (1988) Arrhythmias after repair of secundum atrial septal defect: the influence of surgical modification. Am Heart J 115:629-632

3. Bolens M, Friedli B (1984) Sinus node function and conduction system before and after surgery for secundum atrial septal defect: an electrophysiologic study. Am J Cardiol 53:1415-1420

4. Cherian G, Uthaman CB, Durairaj M, et al. (1983) Pulmonary hypertension in isolated secundum atrial septal defect: high frequency in young patients. Am Heart $J$ 105:952-957

5. Du ZD, Hijazi ZM, Kleinmann CS, Silvermann NH, Larntz K (2002) Comparison between transcatheter and surgical closure of secundum atrial septal defect in children and adults. $J \mathrm{Am}$ Coll Cardiol 39:1836-1844

6. Fraser RG, Paré JAP, Paré PD, Fraser RS, Genereux GP (1988) The heart. In: Manke D (ed), Diagnosis of diseases of the chest; Vol 1. W.B. Saunders, Philadelphia, pp 252-253

7. Galal MO, von Bremen K, Sekarski N (2001) Cost-comparison of transcatheter and surgical closure of atrial septal defect in children [abstr]. Proceedings of the 3rd World Congress of Pediatric Cardiology and Cardiac Surgery, Toronto, Canada, p 878

8. Groundstroem KWE, livainen TE, Talvensaari T, Lahtela JT (1999) Late postoperative follow-up of ostium secundum defect. Eur Heart J 20:904-909

9. Haworth SG (1983) Pulmonary vascular disease in secundum atrial septal defect in childhood. Am J Cardiol 51:265-272

10. Hughes ML, Maskell G, Goh TH, Wilkinson JL (2002) Prospective comparison of costs and short term health outcome of surgical versus transcatheter closure of atrial septal defect in children. Heart 88:67-70

11. James FW, Kaplan S, Glueck CJ, et al. (1980) Responses of normal children and young adults to controlled bicycle exercise. Circulation 61:902-912

12. Kugler JD (1990) Sinus node dysfunction. In: Garson A, Bricker JT, McNamara I (eds), The science and practice of pediatric cardiology. 1st ed. Lea \& Fabiger, Philadelphia/ London, pp 1751-1785

13. Mandelik J, Moodie DS, Sterba R, et al. (1994) Long-term follow-up of children after repair of atrial septal defects. Cleve Clin J Med 61:29-33

14. Meijboom F, Hess J, Szatmari A, et al. (1993) Long-term follow-up (9 to 20 years) after surgical closure of atrial septal defect at a young age. Am J Cardiol 72:1431-1434

15. Meyer RA, Korfhagen JC, Covitz W, Kaplan S (1982) Longterm follow-up study after closure of secundum atrial septal defect in children: an echocardiographic study. Am J Cardiol 50:143-148

16. Morris CD, Menashe VD (1991) 25-year mortality after surgical repair of congenital heart defect in childhood. JAMA 266:3447-3452

17. Murphy JG, Gersh BJ, McGoon MD, et al. (1990) Long-term outcome after surgical repair of isolated atrial septal defect. $N$ Engl J Med 323:1645-1650

18. Pastorek JS, Allen HD, Terrance D (1994) Current outcomes of surgical closure of secundum atrial septal defect. Am J Cardiol 74:75-77

19. Puech P, Latour H, Olivier G, Giraud G (1960) L'hypertension arterielle pulmonaire primitive. II. Association à la communication interauriculaire. Arch Mal Coeur Vaiss 53:291-315 
20. Reid JM, Stevenson JC (1967) Cardiac arrhythmias following successful surgical closure of atrial septal defect. Br Heart $J$ 29:742-747

21. Rominger MB, Bachmann GF, Pabst W, Rau WS (1999) Right ventricular volumes and ejection fraction with fast cine MR imaging in breath-hold technique: applicability, normal values from 52 volunteers, and evaluation of 325 adult cardiac patients. J Magn Reson Imaging 10:908-918

22. Roos-Hesselink JW, Meijboom FJ, Spitaels SEC, et al. (2003) Excellent survival and low incidence of arrhythmias, stroke and heart failure long-term after surgical ASD closure at young age: a prospective follow-up study of 21-33 years. Eur Heart $J$ 24:190-197

23. Rostad H, Sørland SJ (1981) Atrial septal defects of secundum type in patients less than 40 years of age: a follow-up study. Acta Med Scand 645 (Suppl):29-35

24. Ruschhaupt DG, Khoury L, Thilenius OG, Replogle RL, Arcilla RA (1984) Electrophysiologic abnormalities of children with ostium secundum atrial septal defect. Am J Cardiol 53:1643-1647

25. Schnittger I, Gordon EP, Fitzgerald PJ, Popp RL (1983) Standardized intracardiac measurements of two-dimensional echocardiography. J Am Coll Cardiol 2:934-938

26. Stöver B (1986) Determination of heart size and measurements of blood vessels in chest imaging of 4-to 15-year-old children with a healthy cardiovascular system. Radiologe 26:259-265

27. Thomson JD, Aburawi EH, Watterson KG, Van Doorn C, Gibbs JL (2002) Surgical and transcatheter (Amplatzer) closure of atrial septal defects: a prospective comparison of results and cost. Heart 87:466-469

28. Visconti KJ, Bichell DP, Jonas RA, Newburger JW, Bellinger DC (1999) Developmental outcome after surgical versus interventional closure of secundum atrial septal defect in children. Circulation 100(19 Suppl):II145-150

29. Young D (1973) Later results of closure of secundum atrial septal defect in children. Am J Cardiol 31:14-22 